\title{
Impact of human immunodeficiency virus (HIV) infection on the progression of liver fibrosis in hepatitis $C$ virus infected patients
}

\author{
A H Mohsen, P J Easterbrook, C Taylor, B Portmann, R Kulasegaram, S Murad, \\ M Wiselka, S Norris
}

Gut 2003;52:1035-1040

See end of article for authors' affiliations

Correspondence to:

Dr A H Mohsen

Department of HIV/GU

Medicine, The Guys Kings'

and St Thomas School of

Medicine, Weston

Education Centre, Denmark

Hill Campus, Cutcombe

Rd, London SE5 9RJ, UK

Abdul.Mohsen@kcl.ac.uk

Accepted for publication 20 February 2003

\begin{abstract}
Objectives: To compare the rate of hepatic fibrosis progression in hepatitis $\mathrm{C}$ virus $(\mathrm{HCV})$ infected and human immunodeficiency virus (HIV)-HCV coinfected patients, and to identify factors that may influence fibrosis progression.

Patients and methods: A total of $153 \mathrm{HCV}$ infected and $55 \mathrm{HCV}$-HIV coinfected patients were identified from two London hospitals. Eligible patients had known dates of HCV acquisition, were HCV-RNA positive, and had undergone a liver biopsy, which was graded using the Ishak score. Univariate and multivariate logistic regression analyses were used to identify factors associated with fibrosis progression rate and the development of advanced fibrosis (stages 3 and 4).

Results: The estimated median fibrosis progression rate was 0.17 units/year (interquartile range (IQR) $0.10-0.25$ ) in HIV-HCV coinfected and 0.13 (IQR 0.07-0.17) in HCV monoinfected patients $(p=0.01)$, equating to an estimated time from HCV infection to cirrhosis of 23 and 32 years, respectively. Older age at infection $(p<0.001)$, HIV positivity $(p=0.019)$, higher alanine aminotransferase (ALT) level $(p=0.039)$, and higher inflammatory activity $(p<0.001)$ on first biopsy were all independently associated with more rapid fibrosis progression. ALT was correlated with histological index $(r=0.35, p<0.001)$. A CD4 cell count $\leqslant 250 \times 10^{6} / /$ was independently associated with advanced liver fibrosis (odds ratio 5.36 (95\% confidence interval 1.26-22.79)) and was also correlated with a higher histological index $(r=-0.42, p=0.002)$.

Conclusion: HIV infection modifies the natural history of HCV by accelerating the rate of fibrosis progression by 1.4 fold, and the development of advanced fibrosis threefold. A low CD4 cell count was independently associated with advanced disease and correlated with higher histological index, which suggests that early antiretroviral therapy may be of benefit in slowing HCV progression in coinfected patients.
\end{abstract}

$\mathrm{N}$ umerous seroprevalence studies have shown a high rate of coinfection with hepatitis $\mathrm{C}$ virus (HCV) among human immunodeficiency virus 1 (HIV-l) infected patients, ranging from $3-15 \%$ in homosexual/bisexual men to approximately $80 \%$ among injecting drug users and 98\% among haemophiliacs. ${ }^{1}$ Introduction of highly active antiretroviral therapy (HAART) has led to a marked reduction in HIV related complications and mortality, and as a result the impact of chronic HCV infection on morbidity and mortality in HIV infected individuals has become more apparent. ${ }^{3-7}$ Since the advent of HAART, several studies have reported a 3-9-fold increase in hepatitis $\mathrm{C}$ related mortality, ${ }^{3-7}$ and HCV has also been implicated in up to $50 \%$ of all deaths among HIV infected individuals. ${ }^{34}$ Several studies have suggested that HIV accelerates the natural history of chronic HCV infection from chronic active hepatitis to cirrhosis, end stage liver disease, and death. ${ }^{8-11}$ However, much of the published data until recently were based on clinical end points, such as decompensated liver disease and in the haemophiliac population. Fewer studies have examined the impact of HIV using defined histological outcomes based on liver biopsies in HCV monoinfected and coinfected patients with known dates of HCV infection. $.^{10} 12-14$ Only two studies to date have used a histological end point system with estimated rates of fibrosis progression, ${ }^{12} 15$ and only one compared HCV and HIV-HCV infected patients. ${ }^{12}$

The main objectives of this study were to investigate the impact of HIV-1 infection on the natural history of HCV by comparing the fibrosis progression rate using a validated his- tological scoring system in HIV-HCV coinfected and HCV infected patients with known dates of HCV infection, and to assess factors that influence HCV progression in both HCV and coinfected patients.

\section{METHODS}

\section{Study population}

HCV monoinfected patients were identified from the database of $709 \mathrm{HCV}$ infected patients who had attended the Kings' College Hospital, Institute of Liver Studies clinic in South London between July 2000 and June 2002. HIV-1 and HCV coinfected patients were identified from HIV-l infected patients who had attended the HIV clinics of two South London hospitals (Kings' College and St Thomas Hospital) and one clinic in Leicester, UK, between January 1994 and June 2002.

Eligible patients were those who were HCV RNA positive; had a known date of HCV acquisition (as defined by the date of first transfusion or date of the first year of injecting drug use (IDU), or the date of the first risk exposure in patients with more than one risk factor); were hepatitis B surface antigen negative; had a liver biopsy available for assessment; and were

Abbreviations: HIV, human immunodeficiency virus; $\mathrm{HCV}$, hepatitis $\mathrm{C}$ virus; HAART, highly active antiretroviral therapy; IDU, injecting drug use : $A L T$, alanine aminotransferase; FPR, fibrosis progression rate; IQR, interquartile range; $O R$, odds ratio. 
naive to interferon therapy pre-biopsy. Patients with other causes of chronic liver disease were excluded. A total of 153 HCV monoinfected and 55 HIV-1-HCV coinfected eligible patients were identified. An additional 85 patients had undergone a liver biopsy but were excluded because the date of HCV infection was unknown $(\mathrm{n}=80)$ or there was insufficient biopsy material for histological scoring $(n=5)$.

\section{Data collection}

For each patient, an epidemiological questionnaire was administered at or near the time of biopsy and used to collect the following items: date of HCV infection, sex, route of infection, highest alcohol intake just prior to biopsy, and use of antiretroviral therapy. In 15 patients a questionnaire was not administered, and in these patients data were abstracted from the medical records. Laboratory results at biopsy or within 90 days of biopsy included HIV viral load, CD4 cell count, alanine aminotransferase level (ALT, normal range 5-55 IU/l), and HCV genotype, and were abstracted from the medical records.

\section{Laboratory assays}

HIV infection was defined by positivity of both ELISA antibodies and viral detection of HIV RNA. Polymerase chain reaction for HCV RNA was by Cobas Amplicor (Roche, New Jersey, USA). HCV genotype was determined using a commercial probe hybridisation assay in $92(60 \%)$ HCV monoinfected and 17 (31\%) HIV-HCV coinfected patients (InnoLipa HCV; Innogenetics, Ghent, Belgium). ${ }^{16}$

\section{Histological scoring}

A single experienced pathologist (BP) blinded to the HIV status of the patient graded all biopsies according to the Ishak scoring system, ${ }^{17}$ which has been widely used in studies of hepatitis $C$ disease progression. ${ }^{12}{ }^{15}$ Liver fibrosis was scored on a scale of 0 to 4 ( $0=$ no fibrosis, $4=$ cirrhosis $)$, and necroinflammatory lesions were graded from 0 to 18 according to the Ishak grading system. A fibrosis progression rate (FPR) per year was calculated for each patient based on the ratio between fibrosis stage and estimated duration of HCV infection in years. ${ }^{12}{ }^{15}$ For example, for a patient with fibrosis stage 1 and a four year duration of infection, the FPR would be $1 / 4$ or 0.25 fibrosis units per year. This approach makes an assumption that there is a linear rate of progression through the different stages although there are few data available to support this. However, the estimated FPR has been used previously in several similar analyses, ${ }^{12}{ }^{15}$ and we therefore adopted the same approach to enable us to compare findings. Six HIV-HCV coinfected patients had an initial and follow up biopsy, and the observed data from these six patients were used to validate the estimated rates of fibrosis progression.

\section{Statistical analysis}

Demographic and laboratory characteristics at biopsy were compared between the HCV monoinfected and HIV-HCV coinfected patients using the $\chi^{2}$ or Fisher's exact test for categorical variables and a non-parametric two sample median test for continuous data. ${ }^{18}{ }^{19}$ An analysis of the distribution of FPRs for monoinfected and coinfected patients showed that the FPR is not normally distributed. We therefore used univariate and multivariate non-parametric (median) regression analysis to compare FPR in HCV and HIV-HCV patients, with adjustment for potentially important demographic and laboratory characteristics such as age, sex, source of HCV infection, alcohol consumption, ALT, and HCV genotype. Only variables with a p value $<0.2$ in the univariate analysis were included in the multivariate model. To confirm the robustness of our findings using non-parametric (median) regression analysis, we also performed further analyses using logistic regression to investigate factors potentially associated with the presence or absence of liver fibrosis stages 3 and 4 in both HIV-HCV and HCV groups combined, and in the subgroup of HIV-HCV coinfected patients. Age at HCV infection, duration of HCV infection, CD4 cell count, and ALT at biopsy were analysed both as continuous variables and as binary variables categorised according to their median values (age at HCV infection $>22 v \leqslant 22$ years, duration of HCV infection at biopsy $>15 v \leqslant 15$ years, CD4 cell count at biopsy $\leqslant 250 v>250 \times 10^{6} /$, ALT level at biopsy $\left.>80 v \leqslant 80 \mathrm{IU} / \mathrm{l}\right)$. Data were analysed using STATA version 6.0, and all $\mathrm{p}$ values stated are two sided.

\section{RESULTS}

\section{Characteristics of the study population}

The characteristics of 153 HCV infected and 55 HIV-HCV coinfected patients are shown in table 1 . In the combined cohort of 208 patients, median duration of HCV infection at biopsy was 15 (interquartile range (IQR) 11-20) years, and median age at biopsy was 38.8 (IQR 33-43.4) years. A total of 73\% were male and $77 \%$ gave a history of previous IDU. Median ALT at biopsy was 78 (48-132) IU/l and genotype 1 accounted for $53 \%$ of all known HCV genotypes.

The demographic and laboratory characteristics of the two groups were similar although monoinfected patients were slightly older at infection $(23 \vee 21$ years; $\mathrm{p}=0.04)$ and had a higher alcohol intake ( $22 \% \vee 7 \%>20$ units/week; $\mathrm{p}=0.02)$ compared with coinfected patients. Among coinfected patients, $39(72 \%)$ had received or were receiving antiretroviral therapy at the time of biopsy, of whom $35(89.7 \%)$ patients were receiving a HAART regimen at the time of biopsy. The most common antiretroviral combinations were protease inhibitor based regimens in $22(42 \%)$, followed by nonnucleoside reverse transcriptase inhibitor based regimens in $13(24 \%)$. Median duration of antiretroviral therapy at the time of biopsy was 41 months (IQR 17.5-60.5).

A higher liver fibrosis score was more frequent in coinfected patients (median 3 (IQR 1-4)) than in HCV infected patients (median $2($ IQR $1-3))(p=0.006)$. Similarly, a higher necroinflammatory grade was found in coinfected (median 5 (IQR 4-7)) compared with HCV monoinfected (median 4 (IQR $3-5))$ patients $(\mathrm{p}=0.002)$.

Fibrosis progression rate in HCV and HIV-HCV infected patients

The median FPR of HCV monoinfected and HIV-HCV coinfected patients was 0.125 (IQR 0.071-0.173) and 0.174 (IQR $0.100-0.250)$ fibrosis units per year $(p=0.01)$, respectively. Based on these estimated median rates of progression and assuming a linear FPR, median time from HCV infection to cirrhosis would be $32.0(23.1-56.3)$ years in HCV monoinfected and 22.98 (16.0-40.0) years in coinfected patients.

Paired liver biopsy samples were available in six interferon naive HIV-HCV coinfected patients. Median interval between biopsies was 2.1 (range 2-6) years, and the median observed FPR was 0.29 fibrosis units per year, equating to time from infection to cirrhosis of 14 years, which is almost twice the estimated FPR based on all 55 coinfected patients.

Table 2 summarises the results of the univariate and multivariate non-parametric (median) regression analyses of FPR in the HCV and HIV-HCV coinfected groups combined. Older age at infection $(p<0.0001)$, HIV positivity $(p=0.019)$, higher ALT level $(\mathrm{p}=0.039)$, and higher inflammatory grade $(\mathrm{p}<0.0001)$ were associated with a more rapid FPR in both the univariate and multivariate analyses. Factors which did not significantly influence FPR were sex, route of HCV infection, level of alcohol consumption, and HCV genotype.

\section{Factors associated with the development of fibrosis in all HCV infected patients}

Table 3 summarises the univariate and multivariate logistic regression analysis of factors associated with advanced liver 
Table 1 Characteristics of HIV-HCV positive and HCV infected patients at liver biopsy

\begin{tabular}{|c|c|c|c|c|c|}
\hline \multirow{2}{*}{$\begin{array}{l}\text { Factor } \\
\text { Male }\end{array}$} & \multicolumn{2}{|c|}{ HCV monoinfected $(n=153)$} & \multicolumn{2}{|c|}{ HIV-HCV coinfected $(n=55)$} & \multirow{2}{*}{$\frac{p \text { Value }}{0.90}$} \\
\hline & 110 & (71.89\%) & 40 & (72.72\%) & \\
\hline Caucasian & 145 & (95.27\%) & 50 & (90.90\%) & 0.20 \\
\hline Estimated age at $\mathrm{HCV}$ infection (y) (median (IQR)) & 23 & (19-29) & 21 & $(17-24)$ & 0.04 \\
\hline Age at biopsy (y) (median (IQR)) & \multicolumn{2}{|c|}{$39.75(34-46)$} & \multicolumn{2}{|c|}{$37.56(32-41)$} & 0.08 \\
\hline \multicolumn{5}{|l|}{ Route of HCV transmission } & \multirow[t]{3}{*}{0.79} \\
\hline Injecting drug user & 117 & $(76.47 \%)$ & 43 & $(78.18 \%)$ & \\
\hline Transfusion & 36 & (23.52\%) & 12 & (21.82\%) & \\
\hline Duration of HCV infection (y) (median (IQR)) & 15 & $(11-20)$ & 16 & $(9-20)$ & 0.19 \\
\hline $0-10$ & 36 & $(23.52 \%)$ & 18 & $(32.72 \%)$ & \\
\hline $11-20$ & 79 & (51.63\%) & 30 & $(54.45 \%)$ & \\
\hline $21-30$ & 29 & (18.95\%) & 7 & $(12.72 \%)$ & \\
\hline$>30$ & 9 & $(5.88 \%)$ & 0 & $(0 \%)$ & \\
\hline \multicolumn{5}{|l|}{ Maximum alcohol consumption before biopsy (unit/week) } & \multirow[t]{4}{*}{0.02} \\
\hline None & 80 & $(52 \%)$ & 37 & $(67 \%)$ & \\
\hline $1-20$ & 39 & $(26 \%)$ & 14 & $(26 \%)$ & \\
\hline$>20$ & 33 & $(22 \%)$ & 4 & $(7 \%)$ & \\
\hline ALT at liver biopsy (IU/I) (median (IQR)) & 80 & (47-133) & 73 & $(43-111)$ & 0.45 \\
\hline \multicolumn{6}{|l|}{ HCV genotype } \\
\hline 1 & 48 & $(53 \%)$ & 9 & $(53 \%)$ & \\
\hline $2,3,4$ & 44 & $(47 \%)$ & 8 & $(47 \%)$ & \\
\hline CD4 cell count at biopsy (median (IQR)) & \multicolumn{2}{|l|}{-} & 320 & $(200-496)$ & \multirow[t]{2}{*}{-} \\
\hline Use of antiretroviral therapy* & - & & 39 & $(70.90 \%)$ & \\
\hline \multicolumn{6}{|l|}{ Liver histology ${ }^{17}$} \\
\hline Inflammatory grade (median (IQR)) & 4 & $(3-5)$ & 5 & $(4-7)$ & \multirow[t]{4}{*}{0.002} \\
\hline $0-5$ & 127 & $(83 \%)$ & 31 & $(56 \%)$ & \\
\hline $6-18$ & 27 & $(18 \%)$ & 24 & $(44 \%)$ & \\
\hline Fibrosis stage (median (IQR)) & 2 & $(1-3)$ & 3 & $(1-4)$ & \\
\hline 0 & 13 & $(8.96 \%)$ & 2 & $(3.63 \%)$ & \multirow[t]{5}{*}{0.006} \\
\hline 1 & 53 & $(34.64 \%)$ & 14 & $(25.45 \%)$ & \\
\hline 2 & 41 & $(26.79 \%)$ & 11 & $(20.00 \%)$ & \\
\hline 3 & 23 & (15.03\%) & 12 & (21.81\%) & \\
\hline 4 (cirrhosis) & 23 & (15.03\%) & 16 & (30.18\%) & \\
\hline
\end{tabular}

HIV, human immunodeficiency virus; HCV, hepatitis C virus; HAART, highly active antiretroviral therapy; ALT, alanine aminotransferase; IQR, interquartile range.

* 35 patients were receiving HAART at the time of biopsy; 22 were on protease inhibitor based regimens and 13 on non-nucleoside reverse transcriptase inhibitor based regimens.

Table 2 Non-parametric (median) univariate and multivariate regression analyses of demographic and virological factors associated with FPR in both HCV monoinfected and HIV-HCV coinfected patients combined

\begin{tabular}{|c|c|c|c|c|}
\hline Factor & Univariate, coefficient $(95 \% \mathrm{CI})$ & $\mathrm{p}$ Value & Multivariable, coefficient $(95 \% \mathrm{CI})$ & $\mathrm{p}$ Value \\
\hline Age at HCV infection (y) & $0.0038(0.002-0.0054)$ & $<0.0001$ & $0.0044(0.0029-0.0059)$ & $<0.0001$ \\
\hline Sex (male $v$ female) & $0.0095(0.0043-0.023)$ & 0.575 & - & - \\
\hline Source of HCV (IDU $v$ transfusion) & $0.020(0.0236-0.0646)$ & 0.360 & - & - \\
\hline HIV positive & $0.0489(0.006-0.091)$ & 0.005 & $0.0344(0.0056-0.0633)$ & 0.019 \\
\hline Alcohol consumption & $0.0008(-0.0008-0.001)$ & 0.616 & - & - \\
\hline ALT level at liver biopsy & $0.0002(0.00004-0.0004)$ & 0.014 & $0.0001(0.00003-0.00035)$ & 0.039 \\
\hline HCV genotype (1 $v$ others) & $0.0000(-0.0309-0.0309)$ & 1 & - & - \\
\hline Inflammatory grade & $0.023(0.013-0.033)$ & $<0.0001$ & $0.0224(0.0149-0.0300)$ & $<0.0001$ \\
\hline
\end{tabular}

HIV, human immunodeficiency virus; HCV, hepatitis C virus; IDU, injecting drug use; ALT, alanine aminotransferase; FPR, fibrosis progression rate. Duration of HCV infection was excluded from this analysis as it was used to derive FPR and is therefore highly correlated with fibrosis progression rate.

fibrosis (stages 3 and 4) in both HCV monoinfected and HIVHCV coinfected patients. Consistent with our findings in the analysis of FPR, the same three factors were independently associated with advanced liver fibrosis in the multivariate logistic regression analysis: HIV positivity (odds ratio (OR) 2.88 (95\% confidence interval (CI) $1.65-6.19))$, ALT $>80 \mathrm{IU} /$ (OR 3.20 (95\% CI 1.65-6.19)), and duration of HCV infection $>15$ years (OR 4.07 (95\% CI 2.13-7.77)). However, in the logistic regression analysis we did not find an association with older age at HCV acquisition, even when this was analysed as a continuous variable.

To further investigate the nature of the relationship between ALT and the development of fibrosis, we examined the correlation between ALT level and histological score which revealed a positive correlation $(r=0.35, \mathrm{p}<0.001)$. There was also a correlation with necroinflammatory grade $(r=0.33, \mathrm{p}<0.001)$ and fibrosis stage $(r=0.3, \mathrm{p}<0.001)$.
Factors associated with the development of fibrosis in HIV-HCV coinfected patients (table 4)

Univariate logistic regression analysis identified three factors associated with advanced liver fibrosis (stages 3 and 4): duration of $\mathrm{HCV}$ infection >15 years (OR 3.07 (95\% CI 1.01-9.25), CD4 count $\leqslant 250$ cells $\times 10^{6} / 1$ (OR 3.57 (95\% CI $1.13-$ 11.25)), and ALT >80 IU/l (OR 4.44 (95\% CI 1.36-14.46)). In a multivariate logistic regression analysis, a CD4 count $>250$ cells $\times 10^{6} / \mathrm{l}$ at the time of biopsy was the only independent factor associated with advanced fibrosis (OR 5.36 (95\% CI $1.26-$ 22.79)). This was further supported by an inverse correlation between CD4 count $(r=-0.42, \mathrm{p}=0.002)$ and histology index.

\section{DISCUSSION}

In this analysis of $153 \mathrm{HCV}$ monoinfected and 55 HIV-HCV coinfected patients using the most widely adopted histological classification, our main finding was that liver fibrosis 
Table 3 Univariate and multivariate logistic regression analyses of factors associated with advanced liver fibrosis (stages 3 and 4) in both HCV monoinfected and HIV-HCV coinfected patients combined

\begin{tabular}{|c|c|c|c|c|}
\hline Factor & $\begin{array}{l}\text { Univariate, } \\
\text { OR (95\% CI) }\end{array}$ & $p$ Value & $\begin{array}{l}\text { Multivariate, } \\
\text { OR }(95 \% \mathrm{Cl})\end{array}$ & $\mathrm{p}$ Value \\
\hline \multicolumn{5}{|c|}{ Age at HCV infection* (y) } \\
\hline$\leqslant 22$ (ref) & 1 & & & \\
\hline$>22$ & $0.91(0.51-1.61)$ & 0.818 & - & - \\
\hline \multicolumn{5}{|c|}{ 年 } \\
\hline Female (ref) & 1 & & & \\
\hline Male & $0.93(0.50-1.86)$ & 0.838 & - & - \\
\hline \multicolumn{5}{|c|}{ Route of HCV transmission } \\
\hline Transfusion (ref) & 1 & & & \\
\hline IDU & 1.25 (0.61-2.39) & 0.509 & - & - \\
\hline HIV positivity & $2.68(1.40-5.12)$ & 0.003 & $2.88(1.65-6.19)$ & 0.004 \\
\hline \multicolumn{5}{|l|}{ Duration of HCV (y) } \\
\hline$\leqslant 15$ (ref) & 1 & & & \\
\hline$>15$ & 4.67 (2.52-8.83) & $<0.0001$ & $4.07(2.17-7.77)$ & $<0.0001$ \\
\hline \multicolumn{5}{|l|}{ ALT (IU/I)† } \\
\hline$\leqslant 80$ (ref) & 1 & & & \\
\hline$>80$ & $2.96(1.63-5.37)$ & $<0.0001$ & 3.20 (1.65-6.19) & 0.001 \\
\hline \multicolumn{5}{|c|}{ Alcohol (units/week)‡ } \\
\hline$\leqslant 20$ (ref) & 1 & & & \\
\hline$>20$ & 1.31 (0.77-2.65) & 0.382 & - & - \\
\hline \multicolumn{5}{|l|}{ Genotype } \\
\hline $2,3,4$ (ref) & 1 & & & \\
\hline 1 & $1.16(0.54-2.57)$ & 0.669 & - & - \\
\hline
\end{tabular}

progressed 1.4-fold faster in HIV-HCV coinfected than HCV monoinfected patients. This translates to an estimated time from HCV infection to cirrhosis of 23 and 32 years, respectively. However, the observed fibrosis progression in patients with paired biopsies was even more rapid, with a median of only 14 years from infection to cirrhosis. Older age at HCV infection, together with longer duration of HCV infection and higher ALT level at biopsy were independently associated with faster fibrosis progression. These findings were all confirmed in the logistic regression analysis of the development of histological stage 3 and 4 fibrosis, except for older age. In HIV-HCV coinfected patients, a low CD4 count $<250 \times 10^{6} / 1$ cells was also independently associated with both advanced liver disease and higher histological index.

The 1.4-fold increase in FPR with HIV positivity is highly consistent with the 1.44- and 1.4-fold increases reported by Benhamou and colleagues ${ }^{12}$ and Arizcorreta and colleagues, ${ }^{20}$ respectively. HIV seropositivity was also associated with a threefold increase in the development of advanced fibrosis, which is in agreement with previous reports. ${ }^{13} 1420$

In coinfected patients, we found that a low CD4 count $\leqslant 250 \times 10^{6} / 1$ cells at biopsy was associated with a fivefold increase in the presence of advanced liver fibrosis independent of both duration of HCV infection and other known risk factors. Three other studies have also investigated and confirmed a similar association between level of immunosuppression and the severity of HCV infection, ${ }^{162122}$ but only one examined the CD4 count during follow up and prior to biopsy. In this study of 80 coinfected patients, a count of $<200$ cells during follow up was associated with a fourfold increase in the risk of cirrhosis. ${ }^{16}$ However, in contrast with our findings of an inverse correlation between the CD4 cell count and histology index, they did not find an association between the presence of necroinflammatory liver lesions and CD4 cell count. Overall, these observations are consistent with the more rapid progression of disease among other immunocompromised patients such as liver transplant recipient $^{23}$ or those with hypogammaglobulinaemia. ${ }^{24}$ The pathogenic mechanism underlying this relationship is unknown but one hypothesis is that CD4 cell depletion may lead to changes in the intrahepatic cytokine profile, with a predominance of a Th2 pattern, which may then in turn activate hepatic stellate cells and collagen deposition, resulting in cirrhosis. ${ }^{21}$ We did not assess HCV load in our study population but some studies have reported higher levels of HCV-RNA in patients with low CD4 cell counts, ${ }^{16}{ }^{25-27}$ and an association between RNA level and necroinflammatory lesions ${ }^{16}$ but not with fibrosis, suggesting that an increase in RNA levels may play a role in liver damage. Together, these observations provide support for early initiation of antiretroviral treatment in patients coinfected with HCV on the grounds that viral suppression and immune restoration may slow progression of HCV. This strategy is further supported by the observation that a higher CD4 count has been associated with a more favourable response to HCV treatment. ${ }^{28}$

We found that a higher ALT level was independently associated with a faster FPR, and that patients with an ALT level above $80 \mathrm{IU} / \mathrm{l}$ at the time of liver biopsy were three times more likely to develop advanced fibrosis, although this relationship was only of borderline significance among coinfected patients. This was not observed in the two other studies that examined FPR. ${ }^{12}{ }^{15}$ Although patients with abnormal liver function tests have consistently been shown to have more advanced disease compared with those with normal results, ${ }^{29}{ }^{30-33}$ there are conflicting data on the correlation between ALT levels and the severity of liver fibrosis. While two studies failed to show a relationship, ${ }^{34} 35$ other groups have reported a strong association, ${ }^{30} 33$ including one study of 227 patients which found that only $3 \%$ of patients with two consecutive normal ALT values had fibrosis stage 3 or above. We found a moderate correlation $(r=0.35)$ between the ALT value at biopsy and histological activity index, but the positive and negative predictive values for the presence of advanced fibrosis with an ALT level above 80 IU/l were only $64 \%$ and $66 \%$, respectively, although the positive predictive value increased to $87 \%$ when patients were categorised according to elevated or normal ALT before biopsy. It is possible that the predictive value would be even higher if we had categorised patients according to whether the ALT had been persistently raised. However, given that a liver biopsy is an invasive procedure with significant morbidity, ${ }^{36}$ the finding of a persistently raised ALT may assist in the clinical decision when assessing patients for HCV therapeutic intervention. 
Table 4 Univariate and multivariate logistic regression analyses of factors associated with fibrosis (stages 3 and 4 ) in HIV-HCV coinfected patients

\begin{tabular}{|c|c|c|c|c|}
\hline Factor & $\begin{array}{l}\text { Univariate analysis, } \\
\text { OR }(95 \% \mathrm{Cl})\end{array}$ & $\mathrm{p}$ Value & $\begin{array}{l}\text { Multivariate analysis, } \\
\text { OR }(95 \% \mathrm{Cl})\end{array}$ & $\mathrm{p}$ Value \\
\hline \multicolumn{5}{|l|}{ Sex } \\
\hline Female (ref) & 1 & & & \\
\hline Male & $0.79(0.24-2.60)$ & 0.70 & - & \\
\hline \multicolumn{5}{|c|}{ Age at $\mathrm{HCV}$ infection (y) } \\
\hline$\leqslant 22$ (ref) & 1 & & & \\
\hline$>22$ & $0.94(0.31-2.83)$ & 0.91 & - & \\
\hline \multicolumn{5}{|l|}{ Duration of HCV (y) } \\
\hline$\leqslant 15$ (ref) & 1 & & & \\
\hline$>15$ & $3.07(1.01-9.25)$ & 0.04 & $1.84(0.45-7.41)$ & 0.39 \\
\hline \multicolumn{5}{|l|}{ Alcohol (units/week) } \\
\hline$\leqslant 20$ (ref) & 1 & & & \\
\hline$>20$ & $2.96(0.77-11.30)$ & 0.11 & $3.67(0.79-17.05)$ & 0.07 \\
\hline \multicolumn{5}{|c|}{ Route of HCV transmission } \\
\hline Transfusion (ref) & 1 & & & \\
\hline IDU & $2.3(0.60-8.79)$ & 0.22 & - & \\
\hline \multirow{2}{*}{\multicolumn{5}{|c|}{$\begin{array}{l}\text { ALT (IU/I) } \\
\leqslant 80 \text { (ref) }\end{array}$}} \\
\hline & & & & \\
\hline$>80$ & $4.44(1.36-14.46)$ & 0.01 & $3.71(0.90-15.27)$ & 0.06 \\
\hline \multicolumn{5}{|l|}{ Genotype } \\
\hline Other (ref) & 1 & & & \\
\hline Genotype 1 & $2.66(0.19-36.75)$ & 0.46 & - & \\
\hline \multicolumn{5}{|c|}{$\mathrm{CD} 4$ count at liver biopsy $\left(/ \mathrm{mm}^{3}\right)$} \\
\hline$>250$ (ref) & 1 & & & \\
\hline$\leqslant 250$ & $3.57(1.13-11.25)$ & 0.03 & $5.36(1.26-22.79)$ & 0.02 \\
\hline \multicolumn{5}{|c|}{ HIV load at liver biopsy (copies/ml) } \\
\hline$\leqslant 400$ (ref) & 1 & & & \\
\hline$>400$ & $0.99(0.32-0.08)$ & 0.99 & - & \\
\hline \multicolumn{5}{|c|}{ Antiretroviral treatment* } \\
\hline Never (ref) & 1 & & & \\
\hline Ever & $0.82(0.24-2.75)$ & 0.76 & - & \\
\hline
\end{tabular}

Consistent with the findings of other studies, duration of infection $^{1321}$ and older age at infection ${ }^{12}{ }^{15}$ were also independently associated with either faster fibrosis progression or advanced fibrosis, although no association was observed between age at infection and progression to advanced liver fibrosis. In this analysis, sex, HCV transmission group, HIV viral load, alcohol intake, and HCV genotype were not associated with either severe disease or FPR. Only one study has suggested that male sex may influence fibrosis progression ${ }^{15}$ but this was not the case in four other studies. ${ }^{12}{ }^{37-39}$ There has been controversy on the effect of route of HCV infection on disease outcome. One study showed that patients with transfusion associated infection were fourfold more likely to develop decompensation than individuals who were not transfusion recipients ${ }^{40}$ but this has not been confirmed by others. ${ }^{12} 153841$ Our failure to detect an association between alcohol consumption and the presence of liver fibrosis in our cohort of HCV or HIV-HCV infected patients may be because our data were limited to average alcohol intake at or just prior to biopsy. This may also explain why more than half of our study population reported no alcohol intake, as many patients may have discontinued alcohol in response to medical advice following their HCV diagnosis. Three studies have reported a similar lack of association $^{16} 3042$ based on alcohol consumption in the five years $^{1642}$ or six months ${ }^{30}$ prior to biopsy. In contrast, others have found that an alcohol intake at biopsy above $260 \mathrm{~g} / \mathrm{week}$ increased the risk of progression to end stage liver disease by 3.6-fold, ${ }^{43}$ and above $50 \mathrm{~g} / \mathrm{day}^{15}$ was shown to accelerate FPR.

HCV genotype also did not significantly influence fibrosis progression in our study although we had genotype data on only one third of our coinfected patients. This is consistent with the majority ${ }^{12} 1537384445$ but not all studies. ${ }^{46-48}$ Finally, neither exposure to antiretroviral therapy nor type of HAART regimen was associated with faster FPR or the development of severe fibrosis. Only Benhamou et al found an association between the use of protease inhibitor containing regimens and a reduced progression rate ${ }^{41}$ which was not the case for other HAART containing regimens, but this has not been confirmed in other studies. ${ }^{42}$

There are several methodological limitations to the interpretation of our study findings. One concern is the issue of patient selection bias. To address this issue, we first compared our study patients with 501 HCV-PCR positive patients who were assessed in the Kings' liver unit but were not included in the study. Patients in the two groups were similar in age at presentation and sex. Secondly, we found no statistically significant differences in age, sex, ethnic distribution, ALT, alcohol intake at biopsy, or histological index between the study participants and 85 patients who had a liver biopsy but did not fulfil the criteria for inclusion. Therefore, there is no evidence of significant selection bias in the patients we studied.

It is possible that some of our patients may have developed cirrhosis some years before the date of their first liver biopsy, which would lead to underestimation of the rate of progression. Similarly, our assumption that all injecting drug users were infected with HCV during the first year of their drug use may have resulted in an overestimate of the duration of infection in some patients, and so to an underestimate of the progression rate. Finally, in the calculation of FPR, we assumed a linear rate of progression yet it has been suggested that patients may progress faster from stage 3 to 4 than at earlier stages (0-2). Together, these factors may explain why we observed a higher rate of fibrosis progression in patients with paired biopsies compared with the estimated FPRs based on single biopsies from the whole cohort. Finally, as only HCV patients with transfusion acquired infection were tested routinely for HIV, and not patients whose only risk was injecting 
drug use, it is possible that some coinfected IDUs were misclassified as HCV monoinfected. However, as the prevalence of HIV in IDUs in England and Wales is less than 2\%, ${ }^{49}$ such misclassification is unlikely.

In conclusion, HIV infection modifies the natural history of HCV by accelerating fibrosis progression, and actual observed fibrosis progression rates may be significantly higher than the estimated rate. Advanced liver fibrosis and higher inflammatory activity were related to CD4 count, a finding that suggests that early intervention with antiretroviral therapy may be of benefit in slowing HCV progression in coinfected patients.

\section{Authors' affiliations}

A H Mohsen, P J Easterbrook, C Taylor, S Murad, Department of HIV/GU Medicine, The Guys Kings' and St Thomas School of Medicine, London, UK

B Portmann, S Norris, Institute of Liver Studies, Kings' College Hospital, London, UK

R Kulasegaram, Department of Sexual Health, St Thomas Hospital, London, UK

M Wiselka, Department of Infectious Diseases, Leicester Royal Infirmary, Leicester, UK

\section{REFERENCES}

1 Mohsen A, Easterbrook P, Taylor C, et al. Hepatitis C and HIV-1 infection. Gut 2002;4:601-8.

2 Palella FJ, Delaney KM, Moorman AC, et al. Declining morbidity and mortality among patients with advanced human immunodeficiency virus infection. N Engl J Med 1998:338:853-60.

3 Bica I, McGovern B, Dhar R, et al. Increasing mortality due to end-stage liver disease in patients with human immunodeficiency virus infection. Clin Infect Dis 2001;32:492-7.

4 Soriano V, Garcia-Samaniego J, Valencia E, et al. Impact of chronic liver disease due to hepatitis viruses as cause of hospital admission and death in HIV-infected drug users. Eur J Epidemiol 1999;15:1-4.

5 Puoti M, Spinetti A, Ghezzi A, et al. Mortality from liver disease in patients with HIV infection: a cohort study. J Acquir Immune Defic Syndr 2000;24:211-17

6 Martín-Carbonero L, Soriano V, Valencia ME, et al. Impact of chronic viral hepatitis on hospital admission and mortality in HIV-infected patients. AIDS Res Hum Retroviruses 2001;17:1467-71.

7 Cacoub P, Geffray L, Rosenthal E, et al. Mortality among HIV-infected patients with cirrhosis or hepatocellular carcinoma due to hepatitis $C$ virus in French Departments of Internal Medicine/Infectious Diseases in 1995 and 1997. Clin Infect Dis 2001;32:1207-14.

8 Darby SC, Ewart DW, Giangrande PL, et al. Mortality from liver cancer and liver disease in haemophilic men and boys in UK given blood products contaminated with hepatitis C. UK Haemophilia Centre Directors' Organisation. Lancet 1997;350:1425-31.

9 Eyster ME, Diamondstone LS, Lien JM, et al. Natural history of hepatitis $C$ virus infection in multitransfused hemophiliacs: effect of coinfection with human immunodeficiency virus. The Multicenter Hemophilia Cohort Study. J Acquir Immune Defic Syndr 1993;6:602-10.

10 Makris M, Preston FE, Rosendaal FR, et al. The natural history of chronic hepatitis C in haemophiliacs. Br J Haematol 1996;94:746-52.

11 Rockstroh JK, Spengler U, Sudhop T, et al. Immunosuppression may lead to progression of hepatitis $C$ virus associated liver disease in hemophiliacs coinfected with HIV. Am J Gastroenterol 1996;91:2563-8.

12 Benhamou $Y$, Bochet $M$, Di Martino V, et al. Liver fibrosis progression in human immunodeficiency virus and hepatitis $C$ virus coinfected patients. The Multivirc Group. Hepatology 1999;30:1054-8.

13 Pol S, Fontaine $\mathrm{H}$, Carnot $\mathrm{F}$, et al. Predictive factors for development of cirrhosis in parenterally acquired chronic hepatitis $C$ : a comparison between immunocompetent and immunocompromised patients. J Hepatol
1998;29:12-19.

14 Soto B, Sanchez-Quijano A, Rodrigo L, et al. Human immunodeficiency virus infection modifies the natural history of chronic

parenterally-acquired hepatitis $C$ with an unusually rapid progression to cirrhosis. J Hepatol 1997:26:1-5.

15 Poynard T, Bedossa P, Opolon P. Natural history of liver fibrosis progression in patients with chronic hepatitis $C$. Lancet 1997;349:825-32

16 Di Martino V, Rufat $P$, Boyer $N$, et al. The influence of human immunodeficiency virus coinfection on chronic hepatitis $C$ in injection drug users: a long-term retrospective cohort study. Hepatology 2001;34:1193-9.

17 Ishak K, Baptista A, Bianchi L, et al. Histological grading and staging of chronic hepatitis. J Hepatol 1995;22:696-9.

18 Siegl S. Non-Parametric Statistic for Behavioral Sciences. New York: McGraw-Hill, 1956

19 Stata Reference Manual (release 7). Texas: Stata Corporation, 2000.

20 Arizcorreta C, Martinez C, Diaz F, et al. Liver Fibrosis and Cirrhosis in Human Immunodeficiency Virus Co-infected Patients. 14th World AIDS Conference, 6-12 July 2002, Barcelona, Spain (abstract B6036).
21 Puoti $\mathbf{M}$, Bonacini $M$, Spinetti $A$, et al. Liver fibrosis progression is related to $C D 4$ cell depletion in patients coinfected with hepatitis $C$ virus and human immunodeficiency virus. J Infect Dis 2001:183:134-7.

22 Fuster D, Tural C, Romeu J, et al. Factors Associated with Liver Fibrosis in HIV-1 HCV Coinfected on Antiretroviral Therapy. 9th Conference on Retrovirosis and Opportunistic Infection, 10-14 February 2002, Chicago, USA (abstract 646-M)

23 Gane EJ, Portmann BC, Naoumov NV, et al. Long-term outcome of chronic hepatitis $C$ infection after liver transplantation. N Engl J Med 1996;334:815-20.

24 Bjorkander J, Cunningham-Rudles $C$, Lundin $P$, et al. Intravenous immunoglobulin prophylaxis causing liver damage in 16 of 77 patients with hypogammaglobulinemia or IgG subclass deficiency. Am J Med 1988;84:107-11

25 Eyster ME, Fried MW, Di Bisceglie AM, et al. Increasing hepatitis C virus RNA levels in hemophiliacs: relationship to HIV infection and liver disease. Blood 1994:84:1020-3.

26 Thomas DL, Shih JW, Alter HJ, et al. Effect of human immunodeficiency virus on hepatitis $C$ virus infection among injecting drug users. J Infect Dis 1996; 174:690-5.

27 Beld $M$, Penning $M$, Lukashov $V$, et al. Evidence that both HIV and $\mathrm{HIV}$-induced immunodeficiency enhance $\mathrm{HCV}$ replication among $\mathrm{HCV}$ seroconverters. Virology 1998;244:504-12.

28 Soriano V, Garcia-Samaniego J, Bravo R, et al. Interferon alfa for the treatment of chronic hepatitis $\mathrm{C}$ in patients with HIV. Clin Infect Dis 1996;23:585-91.

29 Healey CJ, Chapman RW, Fleming KA. Liver histology in hepatitis C infection: a comparison between patients with persistently normal or abnormal transaminases. Gut. 1995; 37:274-8.

30 Rai R, Wilson LE, Astemborski J, et al. Severity and correlates of liver disease in hepatitis $\mathrm{C}$ virus-infected injection drug users. Hepatology 2002; 35: 1247-55

31 Mathurin P, Moussalli J, Cadranel JF, et al. Slow progression rate of fibrosis in hepatitis $C$ virus patients with persistently normal alanine transaminase activity. Hepatology 1998;27:868-72

32 Shindo M, Arai K, Sokawa Y, et al. The virological and histological states of anti- hepatitis $C$ virus-positive subjects with normal live biochemical values. Hepatology 1995;22:418-25.

33 Renou C, Halfon P, Pol S, et al. Histological features and HLA class II alleles in hepatitis $C$ virus chronically infected patients with persistently normal alanine aminotransferase levels. Gut 2002;51:585-90

34 Haber MM, West $A B$, Haber AD, et al. Relationship of aminotransferases to liver histological status in chronic hepatitis C. Am J Gastroenterol 1995;90:1250-7

35 Kouvatsos P, Doerfler RE, Woodward WC. ALT Does Not Predict Hepatic Fibrosis in HIV/HCV Co-infected Patients on Antiretroviral Therapy. 14th World AIDS Conference, 6-12 July 2002, Barcelona, Spain (abstract WePeB6040)

36 Gilmore IT, Burroughs A, Murray-Lyon IM, et al. Indications, methods, and outcomes of percutaneous liver biopsy in England and Wales: an audit by the British Society of Gastroenterology and the Royal College of Physicians of London. Gut 1995;36:437-41.

37 Mangia A, Cascavilla I, Lezzi G, et al. HCV genotypes in patients with liver disease of different stages and severity. $J$ Hepatol 1997;26:1173-8

38 Mohsen AH, Trent HCV Study Group. The epidemiology of hepatitis C in a UK health regional population of 5.12 million. Gut 2001;5:707-13

39 Garcio-Samaniego J, Soriano V, Castilla J, et al. Influence of hepatitis $C$ virus genotype and HIV infection on histological severity of chronc hepatitis C. The Hepatitis/HIV Study Group. Am J Gastroenterol 1997:92:1130-4

40 Gordon SC, Bayati N, Silverman AL. Clinical outcome of HCV as a function of mode of transmission. Hepatology 1998;28:562-7.

41 Benhamou Y, Di Martino V, Bochet $M$, et al. Factors affecting liver fibrosis in human immunodeficiency virus-and hepatitis $C$ virus-coinfected patients: impact of protease inhibitor therapy. Hepatology 2001;34:283-7.

42 Losada-Arias E, Prieto-Martinez A, Villamil-Cajoto I, et al. Liver Damage in Human Immunodeficiency Virus and Hepatitis $C$ Virus Coinfected Patients: Relationship with Immunological Status. 14th World AIDS Conference, 6-12 July 2002, Barcelona, Spain (abstract ThPeC7508).

43 Thomas DL, Astemborski J, Rai RM, et al. The natural history of hepatitis $C$ virus infection: host, viral, and environmental factors. JAMA 2000;284:450-6.

44 Yamada M, Kakuma S, Yoshioka K, et al. Hepatitis C virus genotypes are not responsible for development of liver disease. Dig Dis Sci 1994;39:234-9.

45 Mita E, Hayashi N, Kanazawa $Y$, et al. Hepatitis $C$ virus genotype and RNA titer in the progression of type $\mathrm{C}$ chronic liver disease. J Hepatol 1994;21:468-73

46 Dusheiko G, Schmilovitz-Weiss H, Brown D et al. 1994. Hepatitis C virus genotypes: an investigation of type-specific differences in geo-graphic origin and disease. Hepatology 1994;19:13-18.

47 Benvegnu L, Pontisso $P$, Cavalletto $D$, et al. Lack of correlation between hepatitis $C$ virus genotypes and clinical course of hepatitis $C$ virus-related cirrhosis. Hepatology 1997;25:211-15.

48 Yee TT, Griffioen A, Sabin CA, et al. The natural history of HCV in a cohort of haemophilic patients infected between 1961 and 1985. Gut 2000:47:845-51.

49 Noone A, Durante AJ, Brady AR, et al. HIV infection in injecting drug users attending centres in England and Wales, 1990-1991. J Acquir Immune Defic Syndr 1993;7:1501-7. 